\title{
Elevated iron stores are associated with HIV disease severity and mortality among postpartum women in Zimbabwe
}

\author{
R Rawat ${ }^{1, *}$,JH Humphrey ${ }^{2,3}, \mathrm{R}$ Ntozini ${ }^{2}, \mathrm{~K} \mathrm{Mutasa}^{2}$, PJ lliff ${ }^{2}$ and RJ Stoltzfus ${ }^{4}$ \\ ${ }^{1}$ Food Consumption and Nutrition Division, International Food Policy Research Institute, $2033 \mathrm{~K}$ Street, \\ Washington, DC 20006, USA: ${ }^{2}$ ZVITAMBO Study Team, Harare, Zimbabwe: ${ }^{3}$ The Johns Hopkins Bloomberg \\ School of Public Health, Department of International Health, Baltimore, MD, USA: ${ }^{4}$ Cornell University, \\ Division of Nutritional Sciences, Ithaca, NY, USA
}

Submitted 2 April 2008: Accepted 6 August 2008: First published online 12 November 2008

\begin{abstract}
Objectives: The relationship between Fe status and HIV infection is complex and poorly understood. While anaemia is a major complication of HIV infection, higher Fe stores may be associated with disease progression. There is limited and conflicting data available from Africa.

Design: Cross-sectional and prospective cohort study.

Setting, subjects and methods: We examined the association between postpartum Fe status (Hb, serum ferritin (SF) and transferrin receptor (TfR)) and viral load (VL) and HIV-related mortality in 643 HIV-positive Zimbabwean women over a period of 12 months.

Results: In non-anaemic women a $\log _{10}$ increase in SF was associated with a $2 \cdot 3$-fold increase in VL $(P=0 \cdot 019)$; this association was absent in anaemic women. In prospective analyses, a $\log _{10}$ increase in SF was associated with a 4-fold increase in mortality by 12 months $(P=0 \cdot 002)$. Hb was negatively associated with VL $(P=0 \cdot 001)$ and mortality $(P=0 \cdot 047)$. The adverse associations between SF and both VL and mortality were found at SF concentrations $>45 \mu \mathrm{g} / \mathrm{l}(P<0.05)$. Controlling for $\alpha_{1}$ acid glycoprotein, a marker of inflammation, attenuated the association between both SF and VL and mortality, but these remained significant. Conclusions: These results are consistent with the hypothesis that high Fe stores have adverse consequences in HIV infection. If adverse consequences are real, our data suggest that they occur at SF concentrations exceeding those consistent with adequate Fe nutriture.
\end{abstract}

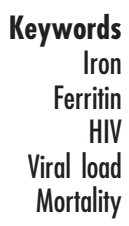

The relationship between anaemia, Fe status and HIV infection is complex and poorly understood. It is well established that anaemia is a common complication of $\mathrm{HIV}$ infection and a strong independent predictor of disease progression and mortality ${ }^{(1-4)}$. Furthermore, correcting anaemia prolongs survival during HIV disease ${ }^{(1,2)}$. However, advanced HIV disease is often characterized by high Fe stores, which may be associated with more rapid progression and higher mortality among HIV-infected individuals ${ }^{(5,6)}$. The hypothesized mechanism is that $\mathrm{Fe}$ deposits in the bone marrow, brain, liver and other organs ${ }^{(7)}$ increase HIV-1 transcription, stimulate microbial growth and impair host immune responses ${ }^{(5,8)}$. It is uncertain if increased $\mathrm{Fe}$ stores are a cause of disease progression or a consequence, and few studies adequately control for the effect of inflammation on indicators of $\mathrm{Fe}$ status. We previously reported that severe anaemia was associated with an increased risk of sexual acquisition of HIV among women who were HIV-negative at delivery ${ }^{(9)}$, further strengthening our need to understand the full range of consequences of Fe deficiency, anaemia and Fe supplementation for both HIV-positive and -negative women living in HIV endemic areas ${ }^{(10)}$.

Much of the evidence that suggests a deleterious effect of Fe during HIV infection comes from studies among European and North American men, in whom Fe deficiency and anaemia are relatively rare (reviewed in references 11 and 12). However, the clinical and programmatic implications of potential harm from $\mathrm{Fe}$ supplementation during HIV infection are greatest for reproductive-aged women in sub-Saharan Africa (SSA), in whom HIV infection and Fe-deficiency anaemia most commonly coexist: $80 \%$ of all HIV-positive women in the world live in SSA and at least half of all pregnant women in SSA are anaemic ${ }^{(3,13,14)}$. Since the major cause of this anaemia is Fe deficiency, WHO has long recommended $\mathrm{Fe} /$ folic acid supplementation for all antenatal women.

The few published reports from SSA that examine the relationship between Fe status and HIV disease severity (as measured by either CD4 count or HIV-1 viral load 
(VL)) have had conflicting results ${ }^{(15-18)}$. Similarly, the association between elevated Fe stores (as measured by serum ferritin (SF)) and HIV-related mortality in developed and developing countries has also been conflicting ${ }^{(18-20)}$. The paucity of studies and the discordant findings available from SSA, together with the clear relevance to programmes recommending Fe supplementation to reproductive-aged women in HIV endemic areas, necessitate additional prospective studies examining the relationship between Fe stores and HIV disease severity and disease progression.

The objectives of the present study were to examine the relationship between Fe stores as measured by SF and (i) HIV plasma VL and (ii) HIV-related mortality by 12 months among HIV-positive postpartum women. Given the known influence of inflammation on Fe indicators, the acute-phase protein $\alpha_{1}$ acid glycoprotein (AGP) was concurrently measured to control for this effect.

\section{Subjects and methods}

\section{Study population}

The study was conducted using archived plasma and serum samples and data collected as part of ZVITAMBO, a clinical trial of postpartum maternal and neonatal vitamin A supplementation, previously reported ${ }^{(9,21,22)}$. Briefly, 14110 mother-infant pairs were recruited within $96 \mathrm{~h}$ of delivery at maternity clinics and hospitals in Harare between November 1997 and January 2000. Baseline characteristics were collected by questionnaire and transcription from hospital records. Maternal mid upper-arm circumference (MUAC) was measured and blood was collected by venepuncture into EDTA and plain (serum) tubes. Plasma and serum were separated and stored at $-70^{\circ} \mathrm{C}$ until used. Mothers were tested for HIV at baseline using two ELISA kits run in parallel. Among women testing HIV-positive at baseline, CD4 cells were enumerated within $48 \mathrm{~h}$ of phlebotomy (Facscount; Becton Dickinson International, Erembodegem, Belgium). $\mathrm{Hb}$ was measured on the same day as blood collection among all women enrolled after 1 October 1999 (about $60 \%$ of the total) using the HemoCue haemoglobinometer (HemoCue, Mission Viejo, CA, USA). Mothers were followed up at 6 weeks, 3 months and then 3 monthly up to 12 months. HIV testing and antiretroviral prophylaxis for HIV-positive antenatal women were not available in Harare public-sector facilities during ZVITAMBO recruitment.

For the present analysis, we drew on archived samples of HIV-positive mothers for whom $\mathrm{Hb}$ had been measured at baseline. To ensure that we could investigate the relationships between Fe status indicators across the spectrum of HIV infection, we selected all mothers with CD 4 counts $<200$ cells $/ \mu$ l and a $20 \%$ random sub-sample of mothers with CD 4 counts of $200-400$ and $>400$ cells $/ \mu l$. Because there were fewer women with CD 4 counts
$<200$ cells/ $\mu \mathrm{l}$ in the larger ZVITAMBO cohort, we oversampled these women. If specimen volume was adequate, SF and serum transferrin receptor (TfR) concentrations were measured by enzyme immunoassay kits (Ramco Laboratories, Houston, TX, USA), and AGP was measured by radial immunodiffusion kits (Kent Laboratories, Bellingham, WA, USA). All assays had a CV less than 10\%. AGP was chosen as an indicator of inflammation because several studies suggest that it best reflects the gradual increase and extended elevation of SF that accompanies the inflammatory response compared with other acute-phase proteins ${ }^{(23)}$. Our final sample size of HIV-positive women for whom we had $\mathrm{Hb}, \mathrm{SF}$, TfR, AGP and CD4 measurements was 643. HIV-1 VL was available on a random sub-set of 375 women.

Because women were recruited into the study immediately after delivery and this was the first point of contact between study staff and study participants, no accurate information on Fe supplementation during pregnancy is available. According to the 1999 Zimbabwe Demographic Health Survey, pregnant women were recommended to take Fe tablets during pregnancy. However, nationally, less than $6 \%$ of pregnant women took ninety or more Fe tablets during their pregnancy, and in Harare this figure was only $1 \%{ }^{(24)}$.

\section{Ethical review}

The Medical Research Council of Zimbabwe, the Committee on Human Research of The Johns Hopkins Bloomberg School of Public Health, and the University Committee on Human Subject at Cornell University approved the study.

\section{Statistical methods}

All statistical analyses were carried out using the STATA version 8 statistical software package (Stata Corporation, College Station, TX, USA). SF and TfR distributions were normalized by $\log _{10}$ transformation; geometric means and $95 \%$ confidence intervals are reported. An AGP cut-off of $>1 \mathrm{~g} / \mathrm{l}$ was used to define inflammation ${ }^{(25)}$; an Hb cut-off of $<110 \mathrm{~g} / \mathrm{l}$ was used to define anaemia ${ }^{(26)}$.

To examine how concentrations of different Fe status indicators varied across the spectrum of HIV infection, ANOVA was used to compare continuous Fe status variables across CD4 categories and HIV RNA quartiles; the $\chi^{2}$ test was used to compare proportions with inflammation across these CD 4 categories. Pairwise comparisons between each pair of means were examined using a post hoc Bonferroni test. We used multivariate linear regression analysis to estimate the association between maternal Fe status and VL. Dummy variables were used to test the statistical effect of categorical variables. Both main effects and interaction between variables were assessed. Where significant interactions were found with a categorical variable, we stratified our analyses.

To examine the association between maternal Fe stores during the immediate postpartum period and mortality 
over the subsequent 12 months, multivariate Cox proportional hazards models were used in which indictors of Fe status were modelled as the independent variable and death as the dependent variable. Other factors that were found to significantly predict death in a larger group of HIV-positive women in the ZVITAMBO trial were included in the model ${ }^{(22)}$. These included maternal age, CD4 count, MUAC, marital status and education. Vitamin A supplementation had no effect on maternal mortality in this trial ${ }^{(22)}$; therefore the treatment arms of the ZVITAMBO trial were not included in our models. Women were censored at the time of death where it occurred $\leq 365 \mathrm{~d}$ postpartum, at the time of last contact for women lost to follow-up prior to 12 months, or at 12 months for women known to be alive at 12 months. Kaplan-Meier survival analysis was used to compare the survival curves across SF categories.

Cause of death was determined from medical records if available or by review of verbal autopsy by the study gynaecologist. Multiple causes were recorded and not ranked. Women whose cause of death could not be ascertained or for whom death was deemed unrelated to HIV were not counted as events in the analyses. Death was categorized as HIV-related if the cause was an AIDSdefining opportunistic infection or malignancy, or if the stated cause was non-specific infection or organ failure. All deaths among patients with CD 4 count $<200$ cells/ $\mu$ l were defined as HIV-related. This methodology has been described elsewhere ${ }^{(27)}$.

\section{Results}

\section{Baseline characteristics}

The prevalence of anaemia was $47 \%$, with a mean $\mathrm{Hb}$ concentration of 110 (SD 19) g/l. Thirty-seven per cent of women had AGP $>1 \mathrm{~g} / \mathrm{l}$ and were classified as experiencing an acute-phase response (geometric mean AGP concentration: $0 \cdot 91 \mathrm{~g} / \mathrm{l}$ ). Fe deficiency, as defined by SF concentration $<15 \mu \mathrm{g} / 1$ in individuals without an acute-phase response (geometric mean SF concentration: $18 \mu \mathrm{g} / \mathrm{l})$ and $<30 \mu \mathrm{g} / \mathrm{l}$ in individuals experiencing an acute-phase response (geometric mean SF concentration: $39 \mu \mathrm{g} / \mathrm{l})^{(26)}$, was $42 \%$; $24 \%$ of women were classified as being Fe-deficient and anaemic (IDA) using $\mathrm{SF}$ and $\mathrm{Hb}$. Using TfR to define Fe deficiency, the prevalence of Fe deficiency (TfR $>8.3 \mu \mathrm{g} / \mathrm{ml}$ ) was $34 \%$ and the prevalence of IDA was $22 \%$.

\section{Cross-sectional association of maternal Fe status indicators with viral load and CD4 count}

Baseline values of $\mathrm{Hb}, \mathrm{SF}$, TfR and AGP were compared across four pre-defined $\mathrm{CD}^{+}$count categories (Table 1). TfR concentrations did not differ across the groups, but $\mathrm{Hb}$ concentrations were significantly higher among women with higher CD 4 cell counts, whereas SF and AGP

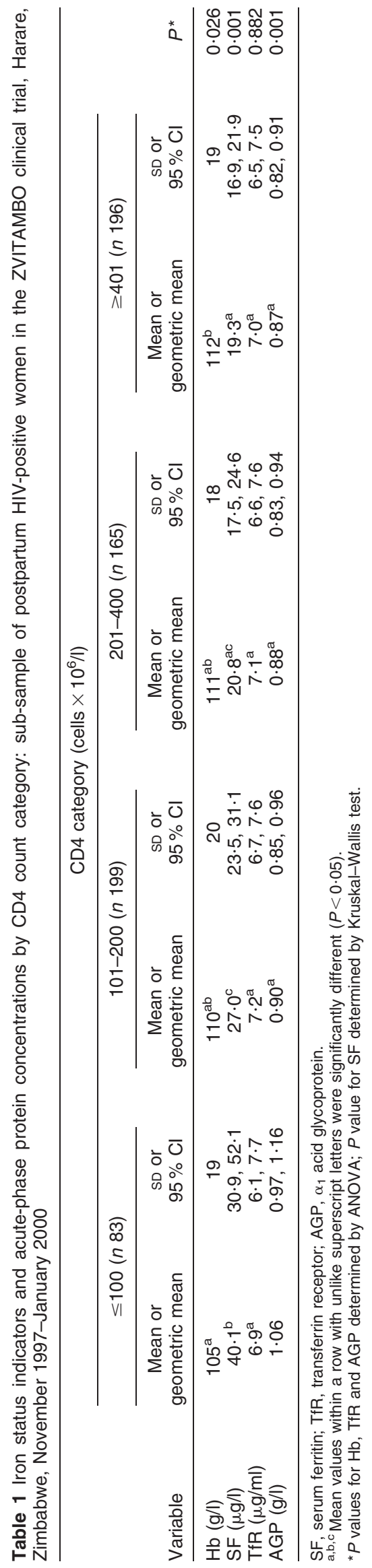


concentrations were significantly lower among women with higher CD 4 cell counts. Similar results were obtained when comparing these indicators across quartiles of VL (data not shown).

In our initial multivariate model, after controlling for AGP and CD4, SF was directly and $\mathrm{Hb}$ was indirectly associated with VL (data not shown). Other covariates associated with VL in univariate analyses were not retained in the model if they had a significance level of $P>0 \cdot 10$ and their inclusion did not significantly alter the SF coefficient. The inclusion of AGP in the final model significantly attenuated the association between SF and VL. The inclusion of AGP in the final model significantly attenuated the association between SF and VL. A $\log _{10}$ increase in SF was associated with a 2-fold higher VL $(\beta=0 \cdot 300, P=0 \cdot 002)$ and each $\mathrm{g} / \mathrm{dl}$ increase in $\mathrm{Hb}$ was associated with an $18 \%$ lower VL $(\beta=-0 \cdot 88, P<0 \cdot 001)$.
Further analysis revealed that the positive association between SF and VL was significantly modified by the presence of anaemia (interaction $P=0 \cdot 029$ ).

No association was found between TfR and VL. Among non-anaemic women, one $\log _{10}$ increase in $\mathrm{SF}$ was associated with a $2 \cdot 27$-fold higher VL $(\beta=0 \cdot 356$, $P=0 \cdot 019$; Table 2 ). The inclusion of AGP into the model significantly attenuated the association between SF and VL. There was no association between increasing SF and VL among anaemic women $(P=0 \cdot 152)$.

To further provide insight into the association between $\mathrm{SF}$ and $\mathrm{VL}$, we divided SF into three categories: $<15$, 15-45 and $>45 \mu \mathrm{g} / \mathrm{l}$ (Fig. 1). After controlling for AGP and CD4 count, anaemic women had significantly higher VL than non-anaemic women within the $\mathrm{SF}<15 \mu \mathrm{g} / 1(2 \cdot 8-$ fold higher, $P=0 \cdot 003)$ and $\mathrm{SF}=15-45 \mu \mathrm{g} / \mathrm{l}(1 \cdot 9$-fold higher, $P=0 \cdot 033$ ) categories, but not in the SF $>45 \mu \mathrm{g} / 1$

Table 2 Predictors of HIV-1 viral load stratified by the presence or absence of anaemia (multivariate analysis): sub-sample of postpartum HIV-positive women in the ZVITAMBO clinical trial, Harare, Zimbabwe, November 1997-January 2000

\begin{tabular}{|c|c|c|c|c|c|c|}
\hline \multirow[b]{2}{*}{ Variable } & \multicolumn{3}{|c|}{$\begin{array}{c}\text { Anaemic } \\
\mathrm{Hb}<110 \mathrm{~g} / \mathrm{l} \\
\left(n 180 ; R^{2}=0.083\right)\end{array}$} & \multicolumn{3}{|c|}{$\begin{array}{c}\text { Not anaemic } \\
\mathrm{Hb} \geq 110 \mathrm{~g} / \mathrm{l} \\
\left(n 195 ; R^{2}=0.144\right)\end{array}$} \\
\hline & $B$ & $10^{B}$ & $P$ & $B$ & $10^{B}$ & $P$ \\
\hline $\log _{10} S F(\mu g / l)$ & $0 \cdot 176$ & $1 \cdot 50$ & $0 \cdot 152$ & 0.356 & $2 \cdot 27$ & 0.019 \\
\hline $\log _{10} A G P(g / l)$ & 0.046 & $1 \cdot 11$ & 0.906 & 0.904 & $8 \cdot 01$ & 0.025 \\
\hline CD4 count (cells $\left.\times 10^{6} / l\right)$ & -0.001 & 0.99 & 0.001 & -0.001 & 0.99 & 0.106 \\
\hline Time since delivery $(\mathrm{h})$ & - & - & - & 0.008 & $1 \cdot 02$ & 0.049 \\
\hline
\end{tabular}

SF, serum ferritin; TfR, transferrin receptor; AGP, $\alpha_{1}$ acid glycoprotein.

Additional variables assessed in the model were age, birth weight, parity and time elapsed between delivery and sample blood draw; time elapsed was retained in the model.

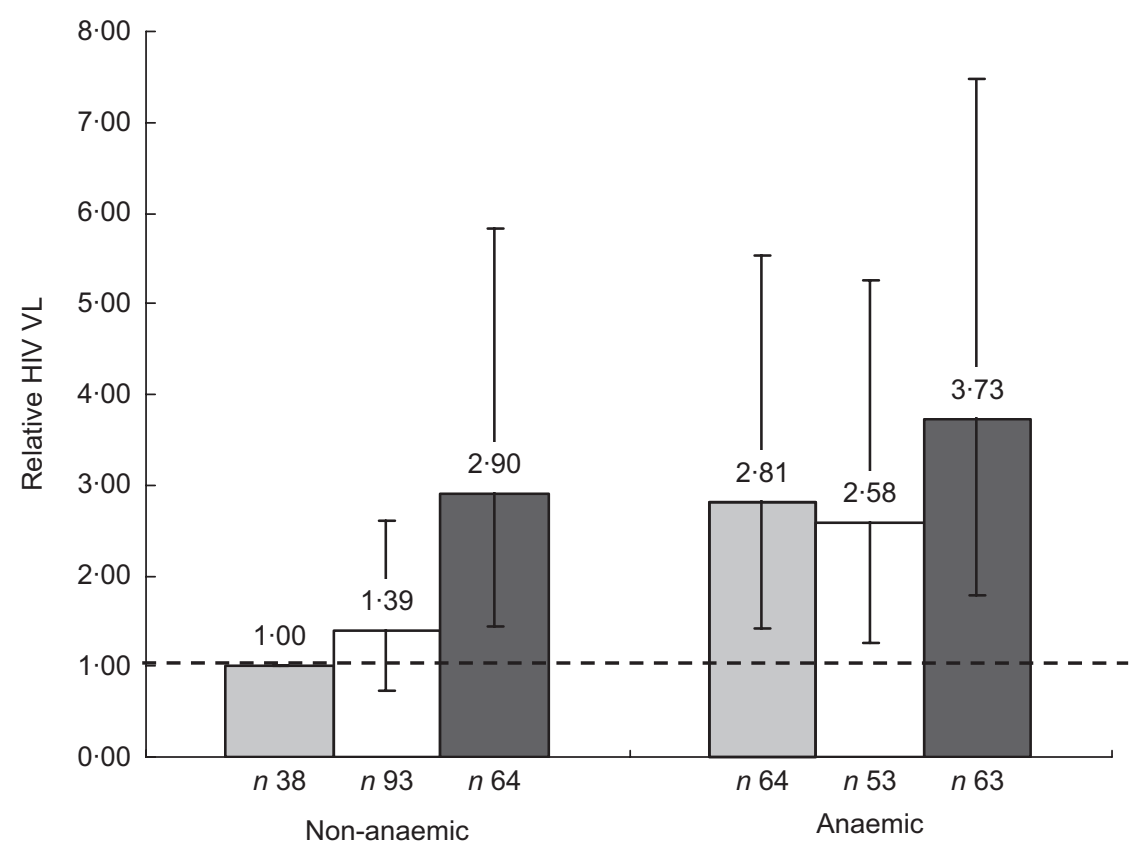

Fig. 1 Relative plasma HIV-1 viral load (VL) by anaemia status (anaemic, $\mathrm{Hb}<110 \mathrm{~g} /$; non-anaemic, $\mathrm{Hb} \geq 110 \mathrm{~g} / \mathrm{l}$ ) and category of serum ferritin (SF) concentration ( $\square,<15 \mu \mathrm{g} / \mathrm{l} ; \square, 15-45 \mu \mathrm{g} / \mathrm{l} ; \square,>45 \mu \mathrm{g} / \mathrm{l}$ ): sub-sample of postpartum HIV-positive women in the ZVITAMBO clinical trial, Harare, Zimbabwe, November 1997-January 2000. Values are relative VL concentrations compared with the reference category of non-anaemic women with $\mathrm{SF}<15 \mu \mathrm{g} / \mathrm{l}$. Vertical bars are $95 \% \mathrm{Cl}$ around the relative VL 
category $(P=0 \cdot 404)$. Additionally, among non-anaemic women, those with SF $>45 \mu \mathrm{g} / 1$ had a $2 \cdot 9$-fold $(95 \% \mathrm{CI}$ $1 \cdot 44,5 \cdot 83)$ higher VL compared with women with $\mathrm{SF}<$ $15 \mu \mathrm{g} / \mathrm{l}$. There was no difference in VL among women with $\mathrm{SF}=15-45 \mu \mathrm{g} / 1 v$. those with $\mathrm{SF}<15 \mu \mathrm{g} / \mathrm{l}$. In contrast, among anaemic women, VL was not significantly different in any of the three SF categories. When excluding all women with elevated AGP concentrations, non-anaemic women with $\mathrm{SF}>45 \mu \mathrm{g} / 1$ had a $>2 \cdot 5$-fold higher VL $(P=0 \cdot 023)$ than those with $\mathrm{SF}<15 \mu \mathrm{g} / 1$.

A second method by which we attempted to control for inflammation was to stratify the analysis according to AGP $<1 \mathrm{~g} / 1 \quad v$. AGP $>1 \mathrm{~g} / 1$ (Table 3). Among women without evidence of inflammation (AGP $<1 \mathrm{~g} / 1$ ), one $\log _{10}$ increase in SF was significantly associated with a $2 \cdot 33$-fold higher VL $(\beta=0 \cdot 369, P=0 \cdot 013)$ after controlling for AGP, $\mathrm{Hb}, \mathrm{CD} 4$ count and birth weight, which was retained in the model. In a similar model but among women with AGP $>1 \mathrm{~g} / \mathrm{l}$, there was no association between SF and VL $(\beta=0 \cdot 191, P=0 \cdot 148)$.

In these models, in addition to stratifying by elevated AGP concentrations, we further included AGP as a continuous variable as there remained a range of AGP concentration among women in these strata. When AGP was not further included as a covariate in models restricted to women with $\mathrm{AGP}<1 \mathrm{~g} / \mathrm{l}$, the association between SF and VL was not altered $(\beta=0 \cdot 376, P=0 \cdot 009$; data not shown). However, when AGP was not included in the models restricted to women with AGP $>1 \mathrm{~g} / \mathrm{dl}$, the relationship between SF and VL did change and was significant $(\beta=0 \cdot 253, P=0 \cdot 026)$.

\section{Association between maternal Fe status indicators and maternal mortality}

Of the 643 women who had complete Fe status measurements, twenty-two were lost to follow-up immediately after recruitment and thirty died during the postpartum year. Cause of death was unknown for four deaths, which were excluded from the analysis. The final sample size included 617 women and twenty-six HIV-related deaths. The cause of death was listed as tuberculosis and/or pneumonia in $81 \%$ (twenty-one deaths) of all cases.

SF was positively and significantly associated with mortality (Table 4). The association between SF and

Table 3 Predictors of HIV-1 viral load stratified by the presence or absence of an acute-phase response (multivariate analysis): sub-sample of postpartum HIV-positive women in the ZVITAMBO clinical trial, Harare, Zimbabwe, November 1997-January 2000

\begin{tabular}{|c|c|c|c|c|c|c|}
\hline \multirow[b]{3}{*}{ Variable } & \multicolumn{6}{|c|}{ Acute-phase response } \\
\hline & \multicolumn{3}{|c|}{$\begin{array}{c}\text { Negative } \\
\text { AGP }<1 \text { g/l } \\
\left(n 219 ; R^{2}=0.097\right)\end{array}$} & \multicolumn{3}{|c|}{$\begin{array}{c}\text { Positive } \\
\text { AGP }>1 \mathrm{~g} / \mathrm{l} \\
\left(n 156 ; R^{2}=0 \cdot 127\right)\end{array}$} \\
\hline & $B$ & $10^{B}$ & $P$ & $B$ & $10^{B}$ & $P$ \\
\hline $\log _{10} S F(\mu \mathrm{g} / \mathrm{l})$ & 0.369 & $2 \cdot 33$ & 0.013 & 0.191 & 1.55 & $0 \cdot 148$ \\
\hline $\mathrm{Hb}(\mathrm{g} / \mathrm{dl})$ & -0.129 & 0.74 & 0.001 & -0.033 & 0.93 & 0.277 \\
\hline $\log _{10} A G P(g / l)$ & 0.156 & $1 \cdot 43$ & 0.782 & 0.611 & $4 \cdot 08$ & 0.372 \\
\hline CD4 count (cells $\left.\times 10^{6} / \mathrm{l}\right)$ & -0.001 & 0.99 & $0 \cdot 152$ & -0.001 & 0.99 & 0.012 \\
\hline Birth weight (per $10 \mathrm{~g}$ ) & - & - & - & -0.003 & 0.99 & 0.032 \\
\hline
\end{tabular}

AGP, $\alpha_{1}$ acid glycoprotein; SF, serum ferritin; TfR, transferrin receptor.

Additional variables assessed in the model were age, birth weight, parity and time elapsed since delivery; birth weight was retained in the model.

Table 4 Predictors of death by 12 months ( $n$ 617; twenty-six HIV-related deaths): sub-sample of postpartum HIV-positive women in the ZVITAMBO clinical trial, Harare, Zimbabwe, November 1997-January 2000

\begin{tabular}{|c|c|c|c|c|c|c|c|c|c|}
\hline \multirow[b]{2}{*}{ Variable } & \multicolumn{3}{|c|}{ Univariate } & \multicolumn{3}{|c|}{ 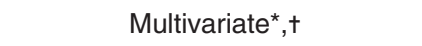 } & \multicolumn{3}{|c|}{ 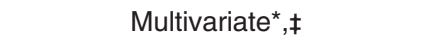 } \\
\hline & $\mathrm{HR}$ & $95 \% \mathrm{Cl}$ & $P$ & HR & $95 \% \mathrm{Cl}$ & $P$ & $\mathrm{HR}$ & $95 \% \mathrm{Cl}$ & $P$ \\
\hline $\log _{10} \operatorname{TfR}(\mu \mathrm{g} / \mathrm{ml})$ & 0.46 & $0.07,3.08$ & $0 \cdot 427$ & & & & & & \\
\hline $\log _{10} S F(\mu \mathrm{g} / \mathrm{l})$ & $10 \cdot 87$ & $5 \cdot 45,21 \cdot 69$ & 0.001 & $9 \cdot 06$ & $4 \cdot 30,19 \cdot 10$ & 0.001 & $4 \cdot 10$ & $1 \cdot 64,10 \cdot 23$ & 0.002 \\
\hline $\mathrm{Hb}(\mathrm{g} / \mathrm{dl})$ & 0.76 & $0.63,0.91$ & 0.003 & 0.73 & $0.59,0.90$ & 0.003 & $0 \cdot 80$ & $0.65,1.00$ & 0.047 \\
\hline \multicolumn{10}{|l|}{ CD4 category } \\
\hline$>200 \times 10^{6} \mathrm{cells} / \mathrm{l}$ & 1.00 & - & & $1 \cdot 00$ & - & & 1.00 & - & \\
\hline$<200 \times 10^{6} \mathrm{cells} / \mathrm{l}$ & $4 \cdot 39$ & $1 \cdot 76,10 \cdot 93$ & 0.001 & $2 \cdot 89$ & $1 \cdot 08,7 \cdot 72$ & 0.035 & 3.05 & $1 \cdot 15,8 \cdot 11$ & 0.025 \\
\hline MUAC $(\mathrm{cm})$ & 0.78 & $0.66,0.92$ & 0.003 & 0.87 & $0.76,0.99$ & 0.043 & 0.88 & $0.77,0.99$ & 0.042 \\
\hline \multicolumn{10}{|l|}{ AGP category } \\
\hline $\mathrm{AGP}<1 \mathrm{~g} / \mathrm{l}$ & $1 \cdot 00$ & - & & & & & & & \\
\hline$A G P>1 \mathrm{~g} / \mathrm{l}$ & 9.91 & $4 \cdot 42,22 \cdot 25$ & 0.001 & & & & & & \\
\hline $\log _{10}$ AGP $(g / l)$ & 2034 & 176,23581 & 0.001 & & & & $53 \cdot 1$ & $2 \cdot 28,1239$ & 0.013 \\
\hline
\end{tabular}

HR, hazard ratio; TfR, transferrin receptor; MAUC, mid upper-arm circumference; SF, serum ferritin; AGP, $\alpha_{1}$ acid glycoprotein.

*All multivariate models included maternal age (years), marital status (coded 0 for stable union, 1 for other) and maternal education (coded 0 for some secondary education, 1 for no secondary education)

tModel does not control for AGP.

‡Model controls for AGP as a continuous $\left(\log _{10}\right)$ variable. 


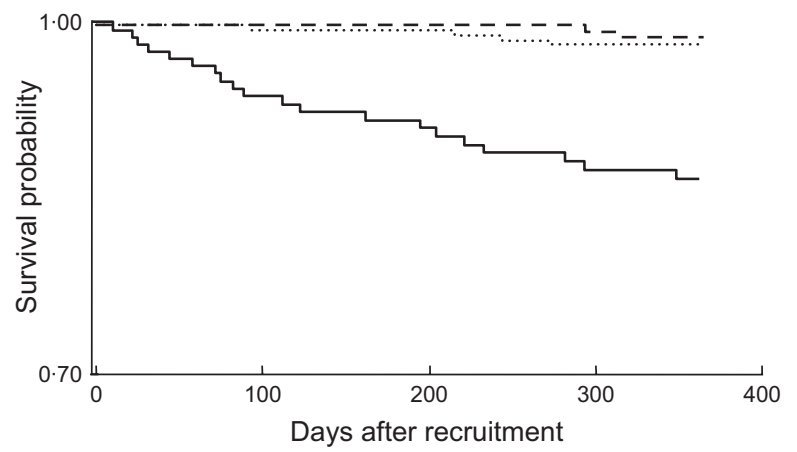

Fig. 2 Kaplan-Meier estimates of the proportion alive by 12 months by category of serum ferritin concentration (---, $<15 \mu \mathrm{g} / \mathrm{l} ; \ldots . . ., 15-45 \mu \mathrm{g} / \mathrm{l} ; \ldots,>45 \mu \mathrm{g} / \mathrm{l})$ : sub-sample of postpartum HIV-positive women in the ZVITAMBO clinical trial, Harare, Zimbabwe, November 1997-January 2000. Log-rank test: $\chi^{2}=41 \cdot 89, P<0 \cdot 001$

mortality was attenuated but remained significant when AGP was included in the model. After adjusting for AGP, CD4 count, $\mathrm{Hb}, \mathrm{MUAC}$, age, educational status and marital status, each $\log _{10}$ increase in SF was associated with a $>4$-fold greater risk of death during the subsequent year $(P=0 \cdot 002)$; this association was greater for non-anaemic women (hazard ratio $(\mathrm{HR})=12.95 ; 95 \%$ CI 1.75 , 95.66; $P=0 \cdot 012)$ than for anaemic women $(\mathrm{HR}=3 \cdot 21 ; 95 \% \mathrm{CI}$ 1.04, 9.91; $P=0.042)$, but the interaction term was not significant $(P=0 \cdot 181)$. We were unable to stratify by AGP $<1 \mathrm{~g} / 1 v$. AGP $>1 \mathrm{~g} / 1$ in our analysis as twenty-one of the twenty-six deaths (81\%) occurred among women with elevated AGP concentrations. As previously seen in the larger ZVITAMBO cohort $^{(22)}$, Hb was inversely associated with mortality. We found no association between mortality and TfR. In the larger ZVITAMBO cohort of approximately 4500 HIV-positive women, increasing maternal age, having at least a high school level of education and being in a stable union/marriage were all protective against mortality.

Separate Kaplan-Meier survival curves were constructed for each of our three SF categories (Fig. 2). In pairwise log-rank tests, the SF $>45 \mu \mathrm{g} / 1$ category was significantly different from each of the other categories $(P<0 \cdot 001$ for the difference with $\mathrm{SF}<15 \mu \mathrm{g} / 1$ and $\mathrm{SF}=15-45 \mu \mathrm{g} / \mathrm{l})$, which were not different from each other $(P=0.569)$. When SF categories were modelled as dummy variables in a multivariate Cox model that controlled for AGP, CD4 count, $\mathrm{Hb}, \mathrm{MUAC}$, age, educational status and marital status, the risk of death was $>5$-fold higher $(\mathrm{HR}=5 \cdot 45$; 95\% CI $1 \cdot 16,25 \cdot 74 ; P=0 \cdot 032)$ at $\mathrm{SF}>45 \mu \mathrm{g} / \mathrm{l}$ compared with $\mathrm{SF}<15 \mu \mathrm{g} / 1$ (data not shown). There was no statistically significant difference in mortality at SF levels of $15-45 \mu \mathrm{g} / 1$ compared with the reference category of $\mathrm{SF}<15 \mu \mathrm{g} / 1(\mathrm{HR}=1 \cdot 50 ; 95 \%$ CI $0 \cdot 27,8 \cdot 41)$.

\section{Discussion}

In the present study of postpartum HIV-positive women, SF was independently associated with HIV-1 VL and
HIV-related maternal mortality during the subsequent year. Controlling for the effects of inflammation on SF using AGP attenuated, but did not eliminate, these associations. These associations were limited to women with SF $>45 \mu \mathrm{g} / 1$, a level which we consider more than adequate from an $\mathrm{Fe}$ nutrition perspective given that the median SF among adult women aged 20-55 years was $28 \mu \mathrm{g} / \mathrm{l}$ in the second National Health and Nutrition Examination Survey ${ }^{(28)}$. Our SF categories were chosen to be informative of $\mathrm{Fe}$ nutrition and represent low or depleted Fe stores $(<15 \mu \mathrm{g} / \mathrm{l})$, a normal range $(15-45 \mu \mathrm{g} / \mathrm{l})$ and a high $\mathrm{Fe}$ storage category $(>45 \mu \mathrm{g} / \mathrm{l})$. Our high $\mathrm{Fe}$ storage category would otherwise not be considered high, and is well below what would be considered Fe overload $\left(\mathrm{SF}>150 \mu \mathrm{g} / \mathrm{l}^{(26)}\right)$; however, given that these women are in the immediate postpartum period (a physiological period when Fe stores would normally be very low), we consider this level to be high and more than adequate.

We believe, in line with other investigators, that the absence of any association between TfR and VL or mortality may be a result of the dual nature of $\operatorname{TfR}^{(19,20)}$. TfR is both an indicator of the severity of Fe insufficiency at the tissue level, as well as a marker of the intensity of erythropoeisis; the latter may be the stronger determinant. Furthermore, TfR concentrations are a marker of Fe insufficiency (and not of excess or elevated $\mathrm{Fe}$ ) only when Fe stores have been exhausted and no other causes of abnormal erythropoeisis are present, which is likely not the case with HIV-infected populations.

\section{Association between Fe status indicators and $\mathrm{HIV}-1$ viral load}

Our data suggest that high Fe stores (measured by SF) may be detrimental, but only among non-anaemic women in whom there is presumably sufficient Fe for the formation of red blood cells. Among these women, excess storage Fe may be enhancing viral replication; the plausible biological role of this potential effect is well documented $^{(5,6,29,30)}$. However, among anaemic women increasing SF was not associated with viral load or mortality. It may be that in HIV-positive anaemic women, Fe is being prioritized for red blood cell production and is thereby not available for viral replication.

We recognize that our use of SF must be interpreted with caution as SF is likely elevated in the face of inflammation. There is no established method of controlling for the positive acute-phase nature of SF, but we addressed this by attempting to control for inflammation in two ways. First, we included AGP as a covariate in our regression models. In these models the inclusion of AGP attenuated the association between SF and VL, but this association remained statistically significant. Clearly, this apparent association is in part due to inflammation. Second, we stratified by AGP concentrations of $<1 \mathrm{~g} / 1 v$. $>1 \mathrm{~g} / \mathrm{l}$. We assumed among women with AGP $<1 \mathrm{~g} / 1$ that SF primarily reflects Fe stores, while among women with 
AGP $>1 \mathrm{~g} / \mathrm{l}, \quad \mathrm{SF}$ may primarily reflect the acute-phase response and may or may not also reflect raised Fe stores. For women with low AGP, SF predicted VL significantly and the magnitude of this effect did not change after further adjusting for AGP, supporting our view that SF reflects $\mathrm{Fe}$ stores and not inflammation among these women. In contrast, among women with elevated AGP concentrations, SF significantly predicted VL only when AGP was not included as a covariate in regression models; adjusting for AGP greatly attenuated this association which was no longer significant.

There are three plausible explanations for our results. First, it is possible that AGP does not adequately control for the acute-phase response and that some reverse causality remains (i.e. HIV infection drives up SF via inflammation). When examining the correlation between SF and AGP, we see that this relationship is much stronger at elevated AGP $(>1 \mathrm{~g} / \mathrm{l})$ concentrations $(r=0 \cdot 423$, $P<0.001)$ compared with normal AGP $(<1 \mathrm{~g} / \mathrm{l})$ concentrations $(r=0 \cdot 142, \quad P=0 \cdot 034)$. Furthermore, our regression analyses described earlier support the inclusion of AGP as a continuous variable to control for the effect of inflammation on SF as this clearly attenuates the association between SF and VL. Therefore, we believe that AGP does capture some of the contribution of elevated SF to VL owing to inflammation (although it may not fully do so) and that its inclusion in our models helps better relate SF to true Fe stores. A second inference that can be proposed is that AGP does in fact control for the acute-phase response, but that advancing HIV disease in turn causes sequestration of Fe leading to increased SF concentrations. Finally, it is plausible that increasing SF as a function of truly increasing Fe stores causes an increase in VL in non-anaemic women. This inference suggests that there are real adverse consequences of increasing $\mathrm{Fe}$ stores with regard to increasing VL. The cross-sectional design of the study prevents us from distinguishing our second $v$. our third inference. What remains undeterminable is the direction of the observed association between $\mathrm{Fe}$ stores and disease progression; cross-sectional studies cannot rule out the possibility that increased storage $\mathrm{Fe}$ (i.e. high SF or bone-marrow $\mathrm{Fe}$ ) is a consequence of HIV progression, rather than its cause.

Three other African studies have directly investigated the relationship between SF and VL. In a cross-sectional analysis of HIV-infected pregnant women in Zimbabwe, investigators showed that women with severely depleted Fe stores $(\mathrm{SF}<6 \mu \mathrm{g} / \mathrm{l})$ had approximately one-third the $\mathrm{VL}$ of women with non-depleted Fe stores (SF $\geq 24 \mu \mathrm{g} / \mathrm{l}$ ) after controlling for inflammation ${ }^{(15)}$. Similarly, among HIV-infected pregnant women in Tanzania, investigators found a strong positive association between SF and VL in both the presence and the absence of inflammation ${ }^{(18)}$. In contrast, a study in Malawi found no relationship between indicators of Fe status (Hb, SF, TfR) and VL in a cross-sectional study of HIV-positive pregnant women ${ }^{(17)}$.

\section{Association between Fe status indicators and mortality}

In the present study population, increasing SF and decreasing $\mathrm{Hb}$ were associated with significant increases in the risk of death by 12 months among HIV-positive postpartum Zimbabwean women. We note that AGP is itself a very strong predictor of death, and that the addition of AGP into the model greatly attenuated the associated risk between increasing SF and death. When AGP was included, further adjusting for CD4 count only marginally attenuated the risk associated with SF. We could not stratify our analyses by elevated AGP concentration as $81 \%$ of deaths occurred in women who had elevated AGP concentration at baseline.

These results suggest that while decreasing $\mathrm{Hb}$ is associated with increased risk of death, an expected and previously described result ${ }^{(3,22)}$, increasing Fe stores may also be associated with increased risk of death. We observed a $\log _{10}$ increase in SF to be associated with a $>4$-fold increase in the risk of death.

There are several studies in developed countries that show an association between SF and HIV-related mortality $^{(7,31-33)}$. More recently, an association between SF and mortality has been shown in a retrospective casecontrol study of an HIV-infected, highly active antiretroviral therapy-naive population in the $\mathrm{USA}^{(19)}$. The investigators found that a $\log _{10}$ increase in SF was associated with a marginally significant 1.67 -fold increase in the odds of death. Two longitudinal studies from SSA examining the association between SF and disease progression and/or mortality have been published recently, with conflicting findings. Among HIV-infected Gambian adults $^{(20)}$, elevated SF predicted a $40 \%$ increase in mortality over 11.5 years. Among pregnant Tanzanian ${ }^{(18)}$ women elevated SF was not associated with a statistically significant increase in the risk of disease progression, although the authors argue that the elevated point estimates coupled with low statistical power do not rule out the possible adverse effects of Fe stores.

Our results support the hypothesis that increasing SF may be associated with a more rapid progression of HIV-1 infection, leading to death. The mechanisms by which this might occur include direct cytotoxicity and immune dysfunction, enhancement of viral replication, and increased susceptibility to certain opportunistic infections and neoplasia $^{(34)}$. A well-recognized consequence of Fe loading is the stimulation of the growth of micro-organisms, including opportunistic pathogens that are associated with HIV infection $^{(5,35,36)}$. There is concern that acquisition of Fe by these pathogens and subsequent increase in microbial growth may itself upregulate transcription of HIV and therefore aid in disease progression ${ }^{(8)}$. Additionally, because Fe loading has been shown to directly inhibit various immune responses ${ }^{(37,38)}$, it is plausible that increasing $\mathrm{Fe}$ stores has the ability to compromise host responses to HIV infection leading to more rapid disease progression. 
The strength of the present analysis is its prospective design which limits the reverse causality argument of advanced HIV disease causing Fe sequestration and in turn increased SF that is inherent in a cross-sectional design. However, like with the adverse association between SF and $\mathrm{VL}$, we cannot rule out the possibility that the use of AGP does not fully control for the effect of inflammation on SF. Clearly the use of AGP attenuates the observed association between SF and mortality, but what remains uncertain is if it eliminates the effect of inflammation on SF.

\section{Conclusions}

These results are consistent with the hypothesis that high Fe stores have adverse consequences within the context of HIV infection. The association with decreasing $\mathrm{Hb}$ was as expected. Controlling for AGP greatly attenuated the association between SF and both VL and progression, but these risks remained and were found at SF levels $>45 \mu \mathrm{g} / \mathrm{l}$. We are unable to determine if the adverse associations that we see at elevated SF concentrations are a consequence of Fe sequestration with advanced infection (in cross-sectional analyses) or if residual effects of the acutephase response remain after controlling for AGP (in both cross-sectional and prospective analyses).

If adverse consequences are real, our data suggest they occur at a level of Fe stores that is more than adequate from an Fe nutrition perspective. These observations are consistent with the idea that, across the spectrum of Fe status, there exists a range associated with optimal host protection. However, we are unable to generalize our findings to other HIV-infected populations such as adult men and children. Therefore, additional studies are needed in HIV-infected populations to elucidate the potential benefit of treating and preventing anaemia with different dosages of Fe supplementation $v$. increasing Fe stores to a level that could be potentially hazardous. This is especially important in populations where health systems lack the capacity for targeted supplementation based on screening for Fe deficiency and anaemia.

\section{Acknowledgements}

Conflict of interest statement: We declare that there are no conflicts of interest.

Contributors: R.R., J.H.H. and R.J.S. designed the study, interpreted the data and wrote the manuscript. R.R. and R.N. were responsible for data management and analysis. R.R. and K.M. carried out laboratory analysis. All authors contributed to the final manuscript.

Funding support: The ZVITAMBO project was supported by the Canadian International Development Agency (CIDA; R/C Project 690/M3688), the United States Agency for International Development (USAID; cooperative agreement number HRN-A-00-97-00015-00 between Johns Hopkins
University and the Office of Health and Nutrition-USAID) and a grant from the Bill and Melinda Gates Foundation (Seattle, WA, USA). Additional funding was received from the Nestlé Foundation (Lausanne, Switzerland), the Rockefeller Foundation (New York, NY, USA) and Cornell University (Ithaca, NY, USA). The Regional Network on AIDS, Livelihoods, and Food Security (RENEWAL) provided support for the time of the first author in preparing this manuscript for submission.

\section{References}

1. Sullivan P (2002) Associations of anemia, treatments for anemia, and survival in patients with human immunodeficiency virus infection. J Infect Dis 185, Suppl. 2, S138-S142.

2. Moore RD, Keruly JC \& Chaisson RE (1998) Anemia and survival in HIV infection. I Acquir Immune Defic Syndr Hum Retrovirol 19, 2-33.

3. O’Brien ME, Kupka R, Msamanga GI, Saathoff E, Hunter DJ \& Fawzi WW (2005) Anemia is an independent predictor of mortality and immunologic progression of disease among women with HIV in Tanzania. J Acquir Immune Defic Syndr 40, 219-225.

4. Kreuzer KA \& Rockstroh JK (1997) Pathogenesis and pathophysiology of anemia in HIV infection. Ann Hematol 75, 179-187.

5. Boelaert JR, Weinberg GA \& Weinberg ED (1996) Altered iron metabolism in HIV infection: mechanisms, possible consequences, and proposals for management. Infect Agents Dis 5, 36-46.

6. Savarino A, Pescarmona GP \& Boelaert JR (1999) Iron metabolism and HIV infection: reciprocal interactions with potentially harmful consequences? Cell Biochem Funct 17, 279-287.

7. de Monye C, Karcher DS, Boelaert JR \& Gordeuk VR (1999) Bone marrow macrophage iron grade and survival of HIV-seropositive patients. AIDS 13, 375-380.

8. Weinberg GA, Boelaert JR \& Weinberg ED (2002) Iron and HIV infection. In Micronutrients and HIV Infection, pp. 135-157 [H Friis, editor]. Boca Raton, FL: CRC Press.

9. Humphrey JH, Hargrove JW, Malaba LC et al. (2006) HIV incidence among post-partum women in Zimbabwe: risk factors and the effect of vitamin A supplementation. AIDS 20, 1437-1446.

10. Doherty CP, Weaver LT \& Prentice AM (2002) Micronutrient supplementation and infection: a double-edged sword? J Pediatr Gastroenterol Nutr 34, 346-352.

11. Clark TD \& Semba RD (2001) Iron supplementation during human immunodeficiency virus infection: a double-edged sword? Med Hypotheses 57, 476-479.

12. Gordeuk VR, Delanghe JR, Langlois MR \& Boelaert JR (2001) Iron status and the outcome of HIV infection: an overview. J Clin Virol 20, 111-115.

13. van den Broek NR, White SA \& Neilson JP (1998) The relationship between asymptomatic human immunodeficiency virus infection and the prevalence and severity of anemia in pregnant Malawian women. Am J Trop Med Hyg 59, 1004-1007.

14. Semba RD, Kumwenda N, Hoover DR, Taha TE, Mtimavalye L, Broadhead R, Eisinger W, Miotti PG \& Chiphangwi JD (2000) Assessment of iron status using plasma transferrin receptor in pregnant women with and without human immunodeficiency virus infection in Malawi. Eur J Clin Nutr 54, 872-877.

15. Friis H, Gomo E, Nyazema N, Ndhlovu P, Krarup H, Madsen PH \& Michaelsen KF (2003) Iron, haptoglobin 
phenotype, and HIV-1 viral load: a cross-sectional study among pregnant Zimbabwean women. J Acquir Immune Defic Syndr 33, 74-81.

16. Olsen A, Mwaniki D, Krarup H \& Friis H (2004) Low-dose iron supplementation does not increase HIV-1 load. J Acquir Immune Defic Syndr 36, 637-638.

17. Semba RD, Taha TE, Kumwenda N, Mtimavalye L, Broadhead R, Miotti PG \& Chiphangwi JD (2001) Iron status and indicators of human immunodeficiency virus disease severity among pregnant women in Malawi. Clin Infect Dis 32, 1496-1499.

18. Kupka R, Msamanga GI, Mugusi F, Petraro P, Hunter DJ \& Fawzi WW (2007) Iron status is an important cause of anemia in HIV-infected Tanzanian women but is not related to accelerated HIV disease progression. J Nutr 137, 2317-2323.

19. Gordeuk VR, Onojobi G, Schneider MF et al. (2006) The association of serum ferritin and transferrin receptor concentrations with mortality in women with human immunodeficiency virus infection. Haematologica 91, 739-743.

20. McDermid JM, Jaye A, Schim van der Loeff MF, Todd J, Bates C, Austin S, Jeffries D, Awasana AA, Whittlex AA \& Prentice A (2007) Elevated iron status strongly predicts mortality in West African adults with HIV infection. J Acquir Immune Defic Syndr 46, 498-507.

21. Humphrey JH, Iliff PJ, Marinda ET et al. (2006) Effects of a single large dose of vitamin A, given during the postpartum period to HIV-positive women and their infants, on child HIV infection, HIV-free survival, and mortality. J Infect Dis 193, 860-871.

22. Zvandasara P, Hargrove JW, Ntozini R et al. (2006) Mortality and morbidity among postpartum HIV-positive and HIVnegative women in Zimbabwe: risk factors, causes, and impact of single-dose postpartum vitamin A supplementation. J Acquir Immune Defic Syndr 43, 107-116.

23. Thurnham DI, Mburu AS, Mwaniki DL \& De Wagt A (2005) Micronutrients in childhood and the influence of subclinical inflammation. Proc Nutr Soc 64, 502-509.

24. Zimbabwean Central Statistical Office and Macro International Inc. (2001) Zimbabwe Demographic and Health Survey 1999, p. 151. Calverton, MD: Central Statistical Office (Zimbabwe) and Macro International Inc.

25. Filteau SM, Morris SS, Abbott RA, Tomkins AM, Kirkwood BR, Arthur P, Ross DA, Gyapong JO \& Raynes JG (1993) Influence of morbidity on serum retinol of children in a community-based study in northern Ghana. Am J Clin Nutr 58, 192-197.
26. World Health Organization (2001) Iron Deficiency Anaemia. Assessment, Prevention, and Control. A Guide for Programme Managers. Geneva: WHO.

27. Cohen MH, French AL, Benning L, Kovacs A, Anastos K, Young M, Minkoff H \& Hessol NA (2002) Causes of death among women with human immunodeficiency virus infection in the era of combination antiretroviral therapy. Am J Med 113, 91-98.

28. Gibson RS (2005) Assessment of iron status. In Principles of Nutritional Assessment, 2nd ed., pp. 443-447. New York: Oxford University Press.

29. Georgiou NA, van der Bruggen T, Oudshoorn M, Nottet HS, Marx JJ \& van Asbeck BS (2000) Inhibition of human immunodeficiency virus type 1 replication in human mononuclear blood cells by the iron chelators deferoxamine, deferiprone, and bleomycin. I Infect Dis 181, 484-490.

30. van Asbeck BS, Georgiou NA, van der Bruggen T, Oudshoorn M, Nottet HS \& Marx JJ (2001) Anti-HIV effect of iron chelators: different mechanisms involved. J Clin Virol 20, 141-147.

31. Costagliola DG, de Montalembert M, Lefrere JJ et al. (1994) Dose of desferrioxamine and evolution of HIV-1 infection in thalassaemic patients. BrJ Haematol 87, 849-852.

32. Salhi Y, Costagliola D, Rebulla P, Dessi C, Karagiorga M, Lena-Russo D, de Montalembert M \& Girot R (1998) Serum ferritin, desferrioxamine, and evolution of HIV-1 infection in thalassemic patients. J Acquir Immune Defic Syndr Hum Retrovirol 18, 473-478.

33. Delanghe JR, Langlois MR, Boelaert JR et al. (1998) Haptoglobin polymorphism, iron metabolism and mortality in HIV infection. AIDS 12, 1027-1032.

34. McDermid JM \& Prentice AM (2006) Iron and infection: effects of host iron status and the iron-regulatory genes haptoglobin and NRAMP1 (SLC11A1) on host-pathogen interactions in tuberculosis and HIV. Clin Sci (Lond) 110, 503-524.

35. Boelaert JR (1996) Iron and infection. Acta Clin Belg 51, 213-221.

36. Weinberg GA (1996) Iron overload as a mechanism for the lowered survival in AIDS patients receiving dapsone-iron protoxalate for secondary prophylaxis of Pneumocystis carinii pneumonia. J Infect Dis 174, 241-242.

37. Brock J (1999) Iron and infection: molecular, physiological and clinical aspects. In Iron and Infection, pp. 289-325. Chichester: John Wiley \& Sons.

38. Weiss G (2002) Iron and immunity: a double-edged sword. Eur J Clin Invest 32, Suppl.1, 70-78. 